\title{
PERSONNEL COMPONENT OF THE REGIONS INNOVATION INFRASTRUCTURE AS A DRIVER FOR THE DEVELOPMENT OF SMART TECHNOLOGIES ${ }^{1}$
}

\author{
Vladimir I. Byvshev \\ Siberian Federal University, Krasnoyarsk, Russian Federation; \\ Krasnoyarsk Regional Fund for Support of Scientific and Technical Activity, Krasnoyarsk, Russian Federation \\ Irina A. Panteleeva \\ Siberian Federal University, Krasnoyarsk, Russian Federation; \\ Krasnoyarsk Regional Fund for Support of Scientific and Technical Activity, Krasnoyarsk, Russian Federation

\section{Kristina V. Parfenteva} \\ Krasnoyarsk Regional Fund for Support of Scientific and Technical Activity, Krasnoyarsk, Russian Federation
}

\section{Danil I. Uskov}

Krasnoyarsk Regional Fund for Support of Scientific and Technical Activity, Krasnoyarsk, Russian Federation

\begin{abstract}
The processes of digitalization and development of smart technologies today set a new paradigm for the development of economy and society as a whole. From year to year, the market capitalization of companies in the field of digital and smart technologies is growing, which reflects the rapid development of this sphere, but in Russia, the pace of development of the digital sphere is lower than in the leading countries in this area, one of the reasons for the lag is insufficient staffing and brain drain. The purpose of the article is to consider the possibility of developing personnel for digital and smart technologies using the personnel component of the regional innovation infrastructure. As a result of studying the experience of Krasnoyarsk krai, it is concluded that the regional law does not set tasks for the development of the regions human resources infrastructure, although the region has a basis for such development and the human resources component of the innovation infrastructure can act as a driver for the development of smart and digital technologies. However, this requires building a model of the network interaction between postgraduate, higher, secondary, general and additional education, as well as direct coordination with regional authorities and regional innovation infrastructure areas of training that are relevant to development in the region. In addition, coordination may consist in generating demand from the business community for personnel in the field of smart and digital technologies.

Key words: smart technologies, staffing, digital economy, regional innovation infrastructure, digitalization, regional economy, innovative activity.

Citation. Byvshev V.I., Panteleeva I.A., Parfenteva K.V., Uskov D.I. Personnel Component of the Regions Innovation Infrastructure as a Driver for the Development of Smart Technologies. Journal of Volgograd State University. Economics, 2020, vol. 22, no. 2, pp. 96-108. (in Russian). DOI: https://doi.org/10.15688/ek.jvolsu.2020.2.9

\section{КАДРОВАЯ СОСТАВЛЯЮЩАЯ ИННОВАЦИОННОЙ ИНФРАСТРУКТУРЫ РЕГИОНА КАК ДРАЙВЕР РАЗВИТИЯ УМНЫХ ТЕХНОЛОГИЙ ${ }^{1}$}

\section{Владимир Игоревич Бывшев}

Сибирский федеральный университет, г. Красноярск, Российская Федерация;

Красноярский краевой фонд поддержки научной и научно-технической деятельности, г. Красноярск,

Российская Федерация 


\section{Ирина Анатольевна Пантелеева}

Сибирский федеральный университет, г. Красноярск, Российская Федерация;

Красноярский краевой фонд поддержки научной и научно-технической деятельности, г. Красноярск, Российская Федерация

\section{Кристина Владимировна Парфентьева}

Красноярский краевой фонд поддержки научной и научно-технической деятельности, г. Красноярск, Российская Федерация

\section{Данил Игоревич Усков}

Красноярский краевой фонд поддержки научной и научно-технической деятельности, г. Красноярск, Российская Федерация

Аннотация. Процессы цифровизации и развития умных технологий сегодня задают новую парадигму развития экономики и всего общества. Из года в год рыночная капитализация компаний из сферы цифровых и умных технологий растет, что отражает быстрое развитие данной сферы, однако в России темпы развития цифровой сферы ниже, чем в странах-лидерах этого направления, одной из причин отставания является недостаточное кадровое обеспечение и утечка «умов». Целью статьи является рассмотрение возможности развития кадров для цифровых и умных технологий при помощи кадровой составляющей региональной инновационной инфраструктуры. В результате исследования опыта Красноярского края сделан вывод о том, что кадровая составляющая инновационной инфраструктуры способна выступить драйвером развития умных и цифровых технологий. Однако для этого требуется построение модели сетевого взаимодействия между послевузовским, высшим, средним, общим и дополнительным образованием, а также непосредственная координация со стороны региональных властей и региональной инновационной инфраструктуры направлений подготовки, которые актуальны для развития в регионе. Кроме того, координация может заключаться в формировании спроса со стороны бизнес-сообщества на кадры сферы умных и цифровых технологий.

Ключевые слова: умные технологии, кадровое обеспечение, цифровая экономика, региональная инновационная инфраструктура, цифровизация, экономика региона, инновационная деятельность.

Цитирование. Бывшев В. И., Пантелеева И. А., Парфентьева К. В., Усков Д. И. Кадровая составляющая инновационной инфраструктуры региона как драйвер развития умных технологий // Вестник Волгоградского государственного университета. Экономика. - 2020. - Т. 22, № 2. - C. 96-108. - DOI: https://doi.org/10.15688/ ek.jvolsu.2020.2.9

\section{Введение}

Начало 21 в. - время цифровых и умных технологий. «Интеллектуальные» часы, бытовая техника, дома и целые города сегодня являются действительностью. Умные технологии могут обеспечивать эффективное потребление ресурсов и ограничивать вредные выбросы в атмосферу, они оказывают качественное влияние на развитие человеческой цивилизации. Умные технологии способствуют интеллектуальной трансформации личности [Мельянцев, 2017]. Несмотря на столь резкий прорыв в этой сфере, большая часть современного общества способна только использовать готовый продукт умных технологий, но не понимать принципы его работы или тем более самостоятельно участвовать в процессе разработки и внедрения умных технологий [Искусственный интеллект ..., 2019].
На сегодняшний день доля цифровых и умных технологий в экономиках развитых стран постоянно растет, это подтверждает тот факт, что в 2019 г. 5 из 10 компаний-лидеров по рыночной капитализации являются представителями сектора цифровых технологий и только 1 компания - представителем сектора добычи полезных ископаемых [Капитализация 100 ..., 2019]. Если же посмотреть на рейтинг капитализации российских компаний 2019 г., то в нем традиционно 9 из 10 компаний являются представителями сектора по добыче полезных ископаемых и 1 компания (ПАО «Сбербанк») - представителем финансового сектора с высокой долей автоматизации своих бизнес-процессов, а также постоянным развитием экосистемы компании в направлении умных и цифровых технологий [ТОП-100 крупнейших ... , 2019]. Такое поло- 
жение дел говорит о недостаточной развитости этой сферы в России и необходимости ее прорывного развития. Значительная часть продуктов умных технологий разрабатывается в развитых странах и Китае, и пока Россия не может конкурировать с ними.

Одной из причин отставания в развитии умных технологий в России от мировых лидеров является ее недостаточное кадровое обеспечение и утечка «умов». Одним из инструментов, способным повлиять на положение дел в лучшую сторону, является региональная инновационная инфраструктура.

\section{Результаты работы}

Возрастание роли цифровых и умных технологий способствует осуществлению и повышению эффективности инновационных процессов, являющихся основой современного социально-экономического развития и роста как на мировом, так и на государственном и региональном уровне, где наука и инновации становятся главной движущей силой развития умных и цифровых технологий, что определяется Целью 9 ООН: промышленность, инновации, инфраструктура [Резолюция Генеральной ... , 2015], где технический прогресс является основой решения экономических и экологических проблем (создание новых рабочих мест, повышение энергоэффективности, содействие инновационным отраслям). Именно деятельность в сфере цифровых и умных технологий способна обеспечить устойчивую динамику экономического роста за счет выпуска конкурентоспособной инновационной продукции. И здесь особое значение для развития региональной экономики имеет именно инновационная инфраструктура, одной из задач которой является обеспечение развития цифровых и умных технологий, а также инноваций [Аверина и др., 2019].

Согласно Федеральному закону № 127-Ф3 «О науке и государственной научно-технической политике» официальное определение инновационной инфраструктуры выглядит следующим образом: это «совокупность организаций, способствующих реализации инновационных проектов, включая предоставление управленческих, материально-технических, финансовых, информационных, кадровых, кон- сультационных и организационных услуг» [Федеральный закон ..., 2016].

В научных источниках исследуемое понятие инновационной инфраструктуры представлено подобными определениями. Например, в Словаре инновационных терминов под инновационной инфраструктурой понимаются организации, способствующие осуществлению инновационной деятельности (инновационнотехнологические центры, технологические инкубаторы, технопарки, учебно-деловые центры и другие специализированные организации) [Словарь инновационных ... , 2019].

Так, инновационная инфраструктура является одним из основных элементов и механизмов обеспечения функционирования высокотехнологичной экономики, выступает ядром и объединяет три основных этапа продвижения технологий на пути к готовому коммерческому продукту: разработка и производство проектов, необходимых для развития рынка; продвижение и реализация инновационной продукции; коммерциализация технологий [Буянова и др., 2019].

Для развития региональной экономики в инновационном направлении важно, чтобы инновационная инфраструктура состояла из необходимого количества элементов, которые направлены на развитие инновационной деятельности. Определить обеспеченность элементами возможно при помощи классификации элементов инновационной инфраструктуры. Существует несколько способов классификации, одним из которых является типизация оказываемых услуг. Применение последней является самым распространенным в исследованиях, а также базой в официальной трактовке данного термина.

Классификация инновационной инфраструктуры согласно методикам разных авторов в их научных работах представляется следующим образом [Теребова, 2014]:

1. И.Г. Дежина и Б.Г. Салтыков выделяют: экспертно-консалтинговую, финансовую, информационную, материальную и кадровую подсистемы инновационной инфраструктуры [Дежина и др., 2004].

2. Г.В. Шепелев выделяет консалтинговую, информационную, финансовую, кадровую, производственно-технологическую, сбытовую подсистемы [Шепелев, 2005]. 
3. В.А. Балукова и И.А. Садчиков выделяют информационную, финансовую и организационную подсистемы инновационной инфраструктуры [Балукова и др., 2003].

4. В.А. Гневко выделяет финансовую, информационную, координационную, кадровую, производственную подсистемы [Гневко, 2004].

5. Д.И. Кокурин, И.П. Николаева, Г.Д. Ковалев выделяют кредитно-финансовую, институт посредников, специализированные компании и фирмы, фондовый рынок, транспорт и связь [Николаева, 2003].

Согласно методике Национального центра по мониторингу инновационной инфраструктуры научно-технической деятельности [Перечень объектов ..., 2019], которая осуществляет непрерывный мониторинг инновационной инфраструктуры по регионам России, составляющими инновационной инфраструктуры регионов являются (табл. 1):

1) производственно-технологическая;

2) экспертно-консалтинговая;

3) кадровая;

4) информационная;

5) финансовая.

Одним из базовых элементов инновационной инфраструктуры является кадровая составляющая, которая осуществляет развитие системы подготовки кадров по направлениям, обеспечивающим инновационную деятельность, и создает специальные условия, направленные на удержание специалистов на территории.
Рассмотрим кадровую составляющую региональной инновационной инфраструктуры на примере одного из регионов Российской Федерации, а именно Красноярского края. Согласно рейтингам АИРР и Высшей школы экономики Красноярский край входит в 20 инновационно развитых регионов Российской Федерации и обладает развитой инновационной инфраструктурой. Но при более детальном анализе отдельных составляющих каждого рейтинга стоит отметить более низкие позиции Красноярского края по показателям кадрового потенциала и потенциала к цифровизации [Рейтинг инновационных ..., 2018; Рейтинг инновационного ... , 2019].

Инновационная инфраструктура Красноярского края в своей деятельности опирается на Закон Красноярского края «О научной, научно-технической и инновационной деятельности в Красноярском крае» от 01.12.2011, который постоянно актуализируется (последние изменения были внесены 21.11.2019 в редакции закона Красноярского края № 8-3339). В соответствии с вышеуказанным законом основными направлениями государственной поддержки научной, научно-технической, инновационной деятельности в крае являются:

1. Поддержка и развитие научной и инновационной деятельности на территории Красноярского края (создание элементов инновационной инфраструктуры, стимулирования малого и среднего предпринимательства к научной и инновационной деятельности, при-

\section{Составляющие инновационной инфраструктуры по методике МИИРИС}

\begin{tabular}{|l|l|}
\hline \multicolumn{1}{|c|}{ Составляющие } & \multicolumn{1}{c|}{ Элементы } \\
\hline $\begin{array}{l}\text { Производственно-тех- } \\
\text { лологическая состав- }\end{array}$ & $\begin{array}{l}\text { Бизнес-инкубаторы, бизнес-акселераторы, индустриальные парки, инновационно- } \\
\text { промышленные комплексы инновационно-технологические центры, технопарки, } \\
\text { технополисы, центры коллективного пользования, наноцентры, инжиниринговые } \\
\text { центры, другие }\end{array}$ \\
\hline $\begin{array}{l}\text { Экспертно-консалтин- } \\
\text { говая и информацион- } \\
\text { ная составляющая }\end{array}$ & $\begin{array}{l}\text { Центры консалтинга, центры трансфера технологий, центры интеллектуальной соб- } \\
\text { стенности, центры поддержки технологий и инноваций; информационные, анали- } \\
\text { тические, статистические, научно-координационные центры, центры научн-техни- } \\
\text { ческой информации, другие }\end{array}$ \\
\hline $\begin{array}{l}\text { Кадровая составляю- } \\
\text { щая }\end{array}$ & $\begin{array}{l}\text { Высшие учебные заведения: институты, академии, университеты (со статусом науч- } \\
\text { но-исследовательского, федерального университета); специализированные органи- } \\
\text { зации по обучению в сфере инновационной деятельности; опытно-конструкторские } \\
\text { организации }\end{array}$ \\
\hline $\begin{array}{l}\text { Финансовая состав- } \\
\text { ляющая }\end{array}$ & $\begin{array}{l}\text { Бюджетные фонды, венчурные фонды, страховые фонды, другие финансовые ин- } \\
\text { ституты }\end{array}$ \\
\hline
\end{tabular}

Примечание. Составлено по: [Перечень объектов ... , 2019]. 
влечение частных инвестиций в сферу науки и инноваций).

2. Организация и содействие участию в мероприятиях, демонстрирующих результаты научной, научно-технической и инновационной деятельности на территории Красноярского края, а также развитие международного сотрудничества [Закон Красноярского ... , 2011].

Отдельный раздел в законе уделен именно инновационной инфраструктуре Красноярского края, созданной с целью развития инновационной деятельности в крае и создания единой системы трансфера и коммерциализации технологий, способствующей увеличению количества произведенной инновационной продукции на территории Красноярского края.

Как мы видим, региональный закон не ставит перед инновационной инфраструктурой задач по развитию кадрового потенциала региона, хотя в крае есть основа для кадрового развития: 10 организаций высшего образования, федеральный исследовательский центр, детский технопарк «Кванториум» и центры молодежного инновационного творчества [Перечень объектов ..., 2019]. Стоит отметить, что в функционировании кадровой составляющей инновационной инфраструктуры Красноярского края отсутствует сетевое взаимодействие и общие цели и задачи. Одним из рычагов, способствующих отладке сетевого взаимодействия между кадровыми элементами инновационной инфраструктуры Красноярского края, настройке координации элементов со стороны региональных властей может стать федеральный проект «Кадры для цифровой экономики», который является составной частью одного из национальных проектов национальной программы «Цифровая экономика», утвержденной протоколом заседания президиума Совета при Президенте Российской Федерации по стратегическому развитию и национальным проектам от 04.06.2019 № 7. Согласно данному федеральному проекту планируются создание и реализация подходов по содействию гражданам в освоении ключевых компетенций цифровой экономики, обеспечении массовой цифровой грамотности и персонализации образования. В этих целях планируется реализация направления «Кадры для цифровой экономики», которое будет способствовать развитию потенциала в сфере цифровых и умных технологий. К 2024 г. планируется выстроить преемственную на всех уровнях систему образования, включающую выявление и поддержку талантов в области математики и информатики, подготовку высококвалифицированных кадров, отвечающих новым требованиям к ключевым компетенциям цифровой экономики, реализацию программ переподготовки по востребованным профессиям в условиях цифровой экономики, а также перспективных образовательных проектов [Цифровизация экономики ..., 2019]. В настоящее время определены 6 целевых показателей данного федерального проекта с их базовыми значениями (табл. 2).

Таблий 2

\section{Базовые показатели федерального проекта «Кадры для цифровой экономики»}

\begin{tabular}{|l|c|}
\hline \multicolumn{1}{|c|}{ Наименование показателя } & Базовое значение \\
\hline $\begin{array}{l}\text { Доля во Всероссийских проверочных работах заданий, при выполнении которых допус- } \\
\text { кается использование цифровых ресурсов (инструментов, источников, сред, сервисов) } \\
\text { профессиональной или повседневной деятельности, \% }\end{array}$ & 0 \\
\hline $\begin{array}{l}\text { Доля населения, обладающего цифровой грамотностью и ключевыми компетенциями } \\
\text { цифровой экономики, \% }\end{array}$ & 26 \\
\hline $\begin{array}{l}\text { Количество выпускников системы профессионального образования с ключевыми компе- } \\
\text { тенциями цифровой экономики, человек }\end{array}$ & 230000 \\
\hline $\begin{array}{l}\text { Количество специалистов, прошедших переобучение по компетенциям цифровой эко- } \\
\text { номики в рамках дополнительного образования, человек }\end{array}$ & 200000 \\
\hline Место в рейтинге привлечения талантов Тһе Global Таlent Сотреtitiveness Index & 52 \\
\hline $\begin{array}{l}\text { Число принятых на программы высшего образования в сфере информационных техноло- } \\
\text { гий и по математическим специальностям, человек }\end{array}$ & 46000 \\
\hline
\end{tabular}

Примечание. Составлено по: [Паспорт федерального ..., 2019]. 
Данный федеральный проект предполагает свою региональную составляющую, а именно наличие региональных проектов в субъектах Российской Федерации. Исходя из Постановления Правительства РФ от 31.10.2018 № 1288 «Об организации проектной деятельности в Правительстве Российской Федерации» региональный проект - это проект, обеспечивающий достижение целей, показателей и результатов федерального проекта, мероприятия которого относятся к законодательно установленным полномочиям субъекта Российской Федерации, а также к вопросам местного значения муниципальных образований, расположенных на территории указанного субъекта Российской Федерации.

Министерством цифрового развития, связи и массовых коммуникаций подготовлены методические рекомендации по разработке региональных проектов в области цифровой экономики, в соответствии с которыми региональным властям предлагается в число основных показателей региональных проектов «Кадры для цифровой экономики» включить: количество выпускников организаций профессионального образования государственной собственности субъекта Российской Федерации и муниципальной собственности с ключевыми компетенциями цифровой экономики, число принятых в организации высшего образования государственной собственности субъекта Российской Федерации на программы высшего образования в сфере информационных технологий, количество специалистов, прошедших переобучение в организациях профессионального образования государственной собственности субъектов Российской Федерации и муниципальной собственности по компетенциям цифровой экономики в рамках дополнительного образования, и доля государственной итоговой аттестации выпускников организаций государственной собственности субъекта Российской Федерации и муниципальной собственности в форме ЕГЭ или иной с использованием цифровых технологий профессиональной или повседневной деятельности [Паспорт федерального ..., 2019]. Стоит отметить, что на сегодняшний день у региональных властей нет прямых полномочий и возможностей по поддержке федеральных вузов, находящихся на территории регионов, поэтому в показателях региональных проектов присутствуют только организации профессионального образования собственности субъектов или муниципалитетов. Но на прошедшем 6 февраля 2020 г. совместном заседании президиума Госсовета и Совета по науке и образованию был обсужден вопрос о возможности расширения финансирования высших учебных заведений федеральной собственности и необходимости предусмотреть возможность финансирования их со стороны региональных бюджетов. Данная мера направлена на возможность расширения финансирования вузов и подготовку регионам необходимых кадров в том числе для цифровой трансформации экономики [Материалы расширенного ..., 2020].

В июне 2019 г. аналитическим центром при Правительстве Российской Федерации был составлен доклад «О текущем развитии проектов в сфере цифровой экономики Российской Федерации», согласно которому программа развития региона в сфере цифровой экономики разработана или находится в стадии разработки в 34 регионах РФ, в 45 регионах разработка программы еще не начата, а в 7 регионах не предоставили данные о ходе работ в сфере цифровой экономики, в данные 7 регионов вошел и Красноярский край. Портал Красноярского края, посвященный региональному проекту «Кадры для цифровой экономики», на данный момент тоже не содержит целевые региональные показатели по данному проекту [Доклад аналитического ..., 2019].

На основе методических указаний Министерства цифрового развития, связи и массовых коммуникаций и данных Росстата сформируем базовые значения по показателям «количество выпускников системы профессионального образования с ключевыми компетенциями цифровой экономики» и «число принятых на программы высшего образования в сфере информационных технологий и по математическим специальностям» для Красноярского края. Стоит учитывать, что все высшие учебные заведения в Красноярском крае федеральной собственности и фактически невозможно включить данные вузов в базовые показатели регионального проекта, однако с учетом последних тенденций, направленных 
на увеличение участия региона в функционировании федеральных вузов, можно запланировать подготовку кадров за счет регионального бюджета для выполнения показателей проекта. В целом на сегодня показатели по подготовке кадров для цифровой экономики на территории Красноярского края представлены в таблице 3.

С учетом базовых показателей и планируемых показателей федерального проекта, а также базовых показателей по подготовке кадров для цифровой экономики на территории Красноярского края рассчитаем плановые значения показателей для территории Красноярского края, которые обеспечат успешную реализацию федерального проекта в Красноярском крае - таблица 4.
Далее рассмотрим демографический прогноз Росстата на данный период по целевой возрастной группе 18-23 года в таблице 5 [Демографический прогноз ..., 2018].

Исходя из представленных данных проведем сопоставления показателей проекта и показателей демографии на территории Красноярского края, для этого сравним их темпы роста (см. табл. 6).

Стоит отметить, что темп роста показателей проекта «Кадры для цифровой экономики» превышает темп роста демографических показателей. Это означает, что необходимо дополнительное привлечение абитуриентов на программы высшего образования в сфере информационных технологий и по математическим специальностям путем популяризации

Таблица 3

Базовые показатели по подготовке кадров для цифровой экономики на территории Красноярского края

\begin{tabular}{|l|c|c|}
\hline \multicolumn{1}{|c|}{ Наименование показателя } & 2018 & 2019 \\
\hline $\begin{array}{l}\text { Количество выпускников системы профессионального образования с ключевыми } \\
\text { компетенциями цифровой экономики, человек }\end{array}$ & 9062 & 8409 \\
\hline $\begin{array}{l}\text { Число принятых на программы высшего образования в сфере информационных тех- } \\
\text { нологий и по математическим специальностям, человек }\end{array}$ & 1599 & 1682 \\
\hline
\end{tabular}

Примечание. Составлено авторами.

Таблииа 4

Плановые показатели по подготовке кадров для цифровой экономики на территории Красноярского края

\begin{tabular}{|l|c|c|c|c|c|}
\hline \multicolumn{1}{|c|}{ Наименование показателя } & 2020 & 2021 & 2022 & 2023 & 2024 \\
\hline $\begin{array}{l}\text { Количество выпускников системы профессионального образо- } \\
\text { вания с ключевыми компетенциями цифровой экономики, че- } \\
\text { ловек }\end{array}$ & 1091 & 13454 & 16818 & 21863 & 26909 \\
\hline $\begin{array}{l}\text { Число принятых на программы высшего образования в сфере } \\
\text { информационных технологий и по математическим специаль- } \\
\text { ностям, человек }\end{array}$ & & & & & \\
\hline
\end{tabular}

Примечание. Составлено авторами.

Демографический прогноз Росстата по возрастной группе 18-23 года на территории Красноярского края

\begin{tabular}{|c|c|c|c|c|c|c|}
\hline Возраст & 2019 & 2020 & 2021 & 2022 & 2023 & 2024 \\
\hline 18 & 28203 & 28572 & 30293 & 31305 & 31323 & 30649 \\
\hline 19 & 26776 & 28593 & 28909 & 30632 & 31616 & 31604 \\
\hline 20 & 27885 & 27022 & 28936 & 29267 & 31058 & 32059 \\
\hline 21 & 27023 & 28078 & 27238 & 29219 & 29586 & 31494 \\
\hline 22 & 29167 & 27119 & 28239 & 27412 & 29429 & 29820 \\
\hline 23 & 29740 & 29092 & 27177 & 28347 & 27529 & 29553 \\
\hline Итого & 168794 & 168476 & 170792 & 176182 & 180541 & 185179 \\
\hline
\end{tabular}

Примечание. Составлено по: [Демографический прогноз ... , 2018]. 
Кадровая составляющая инновационной инфраструктуры региона

Таблица 6

Темпы роста прогнозных показателей за 2019-2024 годы

\begin{tabular}{|l|c|c|}
\hline \multicolumn{1}{|c|}{ Наименование показателя } & $\begin{array}{c}\text { Общий темп } \\
\text { роста, \% }\end{array}$ & $\begin{array}{c}\text { Средний темп } \\
\text { роста, \% }\end{array}$ \\
\hline $\begin{array}{l}\text { Количество выпускников системы профессионального образования с клю- } \\
\text { чевыми компетенциями цифровой экономики, человек }\end{array}$ & 320,0 & 126,2 \\
\hline $\begin{array}{l}\text { Число принятых на программы высшего образования в сфере информаци- } \\
\text { онных технологий и по математическим специальностям, человек }\end{array}$ & 240,0 & 119,1 \\
\hline Демографический прогноз в возрастной группе 18-23 года & 110,9 & 102,1 \\
\hline
\end{tabular}

Примечание. Составлено авторами.

данных программ, подготовки и введения в образовательный процесс новых отраслевых направлений в сфере информационных технологий, например, «Бизнес-информатика», «Гуманитарная информатика» и «Прикладная информатика», что одновременно обеспечит востребованность таких специалистов на рынке труда в своих отраслях [Алпеева и др., 2019]. Кроме того, необходимо формировать целевые места в высших учебных заведениях по данным направлениям подготовки, причем их формированию может способствовать региональная инновационная инфраструктура. Данные направления подготовки обеспечат региональную экономику специалистами с навыками как отраслевой направленности, так и в области цифровых и умных технологий [Кудрявцева, 2019].

Работа по популяризации данных направлений и профориентационная работа среди школьников уже ведется на территории Красноярского края. Например, элементами региональной инновационной инфраструктуры ведется работа по популяризации среди школьников таких направлений, как робототехника и конструирование, проводит по ним соревнования. Важно отметить, что Красноярск стал единственным российским городом, получившим право на проведение международных робототехнических соревнований в течение 2019-2021 годов.

Другой площадкой, ориентирующей кадры для цифровой экономики, является образовательный проект по бесплатному обучению школьников программированию - «Яндекс. Лицей». В Красноярском крае он реализуется в г. Зеленогорске, Гимназии «Универс» г. Красноярска, АНО «Красноярский детский технопарк «Кванториум», лицей «Перспеспектива». Учебная программа в данном проекте рассчи- тана на два года, в ее рамках учащиеся знакомятся с теорией и осваивают технологии на практике. С программированием школьники знакомятся на примере Python, так как Python один из самых популярных языков программирования в мире. Помимо этого, «Яндекс. Лицей» помогает преподавателям и курирует их работу на протяжении учебного процесса. Курс ведется преподавателями из Красноярского края, которые прошли отбор на соответствие стандартам проекта и получают сопровождение и контроль от Яндекса.

Также в Красноярском крае был реализован проект по открытию «Техношколы» при опорном вузе - Сибирском государственном университете науки и технологий им. академика М.Ф. Решетнева и физико-математической школы при Сибирском федеральном университете.

В Красноярском крае проводятся региональные чемпионаты по профессиональному мастерству, в том числе по специальностям, которые соответствуют вызовам современной экономики, например, такие как промышленная автоматика, мобильная робототехника, изготовление прототипов, разработка мобильных приложений, инженерный дизайн CAD (САПР), программные решения для бизнеса, веб-дизайн и разработка. Конкурс профессионального мастерства проводится в различных категориях: юниоры (моложе 16 лет), молодые профессионалы (16-22 года), навыки мудрых (старше 50 лет). Проведение данного конкурса способствует развитию профессиональных навыков и компетенций, а также профессиональной ориентации молодежи и развитию интереса к высокотехнологичным отраслям экономики.

Количество выпускников системы профессионального образования с ключевыми 
компетенциями в цифровой экономике на территории Красноярского края к 2024 г. планируется увеличить в 3,2 раза, для успешного достижения данного показателя необходимо развитие компетенций в области цифровой экономики по всем направлениям подготовки профессионального образования. Для этого потребуется внесение изменений в действующие образовательные стандарты и программы с введением в них компетенций и предметов, позволяющих приобрести в процессе обучения навыки в сфере цифровой экономики. Стоит отметить, что Агентство стратегических инициатив совместно с Институтом развития образования реализует пилотные проекты о практико-ориентированном дуальном образовании. Преимуществом такого образования является участие работодателей в разработке образовательных программ и требований к профессиональным компетенциям студентов, что позволит своевременно обновлять учебные программы в соответствии с изменяющимися требованиями, повысить качество подготовки кадров, поднять эффективность использования ресурсов, затрачиваемых на подготовку кадров, оптимизировать рынок труда с точки зрения востребованных специальностей, и обеспечить взаимодействие сфер образования с производства. На региональном уровне способствовать реализации такого рода инициатив может региональная инновационная инфраструктура [Дадалко и др., 2018].

\section{Заключение}

В заключение стоит отметить, что кадровая составляющая инновационной инфраструктуры способна выступить драйвером развития умных и цифровых технологий, но для этого требуется построение модели сетевого взаимодействия между послевузовским, высшим, средним, общим и дополнительным образованием, а также непосредственная координация со стороны региональных властей и региональной инновационной инфраструктуры направлений подготовки, которые актуальны для развития в регионе. Кроме того, координация может заключаться в формировании спроса со стороны бизнес-сообщества на кадры сферы умных и цифровых технологий. Проанализированные материалы и показатели свидетельствуют о том, что такая работа должна была начаться еще в 2019 г., но на данный момент большинство регионов не включилось в работу по федеральному проекту «Кадры для цифровой экономики».

\section{ПРИМЕЧАНИЕ}

${ }^{1}$ Исследование выполнено при финансовой поддержке РФФИ в рамках научного проекта № 20-010-00482.

The reported study was funded by RFBR, project no. 20-010-00482.

\section{СПИСОК ЛИТЕРАТУРЫ}

Аверина, И. С. Направления повышения экономической безопасности региона: инновационный аспект / И. С. Аверина, М. Э. Буянова // Экономическая безопасность: правовые, экономические, экологические аспекты : сб. науч. тр. 4-й Междунар. науч.-практ. конф. (Курск, 24 апреля 2019 г.). - 2019. - № ЭБ-04. C. 309-313.

Алпеева, Е. А. Формирование кадров для инновационно-цифровой экономики / Е. А. Алпеева, А. А. Ушенко // Глобальный научный потенциал. - 2019. - № 4 (97). - С. 154-158.

Балукова, В. А. Управление инновационными процессами на предприятиях химической и нефтехимической промышленности / В. А. Балукова, И. А. Садчиков, В. Е. Сомов. - СПб. : Изд-во СПбГИЭУ, 2003. - 147 с.

Буянова, М. Э. Оценка влияния факторов экономической безопасности на инновационную активность региона / М. Э. Буянова, И. С. Аверина // Национальные интересы: приоритеты и безопасность. - 2019. - № 7 (376). C. $1337-1350$.

Гневко, В. А. Региональные проблемы инновационного развития экономики / В. А. Гневко. СПб. : ИУЭ, 2004. -480 c.

Дадалко, В. А. Компетенции для цифровой экономики и трансформация образовательной системы в условиях VI экономического уклада / В. А. Дадалко, Е. Д. Соловкина // Национальные интересы: приоритеты и безопасность. - 2018. - № 5 (362). - С. 913-926.

Дежина, И. Г. Механизмы стимулирования коммерциализации исследований и разработок / И. Г. Дежина, Б. Г. Салтыков // Общество и экономика. - 2004. - № 7. - С. 189-248.

Демографический прогноз по возрастам на 20192024 гг. - Электрон. текстовые дан. - Режим 
доступа: https://krasstat.gks.ru/folder/32970 (дата обращения: 05.03.2020). - Загл. с экрана.

Доклад аналитического центра при Правительстве Российской Федерации от 01.06.2019 г. «О текущем развитии проектов в сфере цифровой экономики Российской Федерации». - Электрон. текстовые дан. - Режим доступа: https:/ /ac.gov.ru/publications?page=8 (дата обращения: 05.03.2020). - Загл. с экрана.

Закон Красноярского края от 01.12.2011 г. № 8-3339 «О научной, научно-технической и инновационной деятельности в Красноярском крае». - Электрон. текстовые дан. - Режим доступа: http://www.krskstate.ru/docs/0/doc/61927 (дата обращения: 05.03.2020). - Загл. с экрана.

Искусственный интеллект и цифровые преобразования в обществе / А. В. Лаврентьева [и др.] // Материаловедение и инженерные науки. -2019 . - № 483. - С. 1-8.

Капитализация 100 крупнейших компаний мира достигла рекордных 21 триллионов долларов. Электрон. текстовые дан. - Режим доступа: https:/www.rbc.ru/business/16/08/2019/5d560 5839a7947e7cd21723b (дата обращения: 05.03.2020). - Загл. с экрана.

Кудрявцева, С. С. Подготовка кадров для регионального промышленного комплекса в условиях цифровой экономики / С. С. Кудрявцева // Казанский педагогический журнал. - 2019. № 5 (136). - С. 25-29.

Материалы расширенного заседания президиума Госсовета и Совета по науке и образованию от 06.02.2020 «Роль регионов в подготовке кадров для экономики и социальной сферы». - Электрон. текстовые дан. - Режим доступа: http:// kremlin.ru/events/president/news/62744/work (дата обращения: 05.03.2020). - Загл. с экрана.

Мельянцев, В. А. Умные технологии, парадокс Солоу и противоречия социально-экономического развития в странах запада и востока в начале XXI в. / В. А. Мельянцев // Восток. Афро-азиатские общества: история и современность. - 2017. - № 3. - С. 162-180.

Николаева, И. П. Ресурсы инноваций: организационный, финансовый, административный / И. П. Николаева. - М. : ЮНИТИ-ДАНА, 2003. $-318 \mathrm{c}$.

Паспорт федерального проекта от 28.05.2019 № 9 «Кадры для цифровой экономики». - Электpoн. текстовые дан. - Режим доступа: https:// digital.gov.ru/ru/activity/directions/866/ (дата обращения: 05.03.2020). - Загл. с экрана.

Перечень объектов инновационной инфраструктуры. - Электрон. текстовые дан. - Режим доступа: https://www.miiris.ru/files/publ/file_5.html (дата обращения: 05.03.2020). - Загл. с экрана.
Резолюция Генеральной Ассамблеи ООН от 21.10.2015 «Преобразование нашего мира: Повестка дня в области устойчивого развития на период до 2030 года». - Электрон. текстовые дан. - Режим доступа: https://www. sdgfund.org/goal-9-industry-innovationinfrastructure (дата обращения: 05.03.2020). Загл. с экрана.

Рейтинг инновационного развития субъектов Российской Федерации. - Электрон. текстовые дан. - Режим доступа: https://issek.hse.ru/ rirr2019 (дата обращения: 05.03.2020). - Загл. с экрана.

Рейтинг инновационных регионов России. - Электрон. текстовые дан. - Режим доступа: https:/ /i-regions.org/reiting/rejting-innovatsionnogorazvitiya/2018 (дата обращения: 05.03.2020). Загл. с экрана.

Словарь инновационных терминов. - Электрон. текстовые дан. - Режим доступа: https:// infosystems.ru/library/slovar_ais_1218/slovar innovaci_1222.html (дата обращения: 05.03.2020). - Загл. с экрана.

Теребова, С. В. Инновационная инфраструктура в регионе: проблемы и направления развития / С. В. Теребова // Экономические и социальные перемены: факты, тенденции, прогноз. - 2014. - № 6 (36). - С. 199-212.

ТОП-100 крупнейших по капитализации компаний России - Рейтинг. - Электрон. текстовые дан. - Режим доступа: https://riarating.ru/ infografika/20190129/630115992.html (дата обращения: 05.03.2020). - Загл. с экрана.

Федеральный закон от 23.08.1996 № 127-Ф3 «О науке и государственной научно-технической политике». - Доступ из справ.-правовой системы «КонсультантПлюс».

Цифровизация экономики: мир, Россия, регионы / И. В. Митрофанова [и др.]. - М. : ДиректМедиа, 2019. - 73 с.

Шепелев, Г. В. Проблемы развития инновационной инфраструктуры / Г. В. Шепелев // Инновации. - 2005. - № 2 (79). - С. 6-15.

\section{REFERENCES}

Averina I.S., Buyanova M.E. Napravleniya povysheniya ekonomicheskoy bezopasnosti regiona: innovatsionnyy aspekt [Directions for Improving the Economic Security of the Region: Innovative Aspect]. Ekonomicheskaya bezopasnost: pravovye, ekonomicheskie, ekologicheskie aspekty: sb. nauch. tr. 4-y Mezhdunar. nauch.-prakt. konf. (Kursk, 24 aprelya 2019 g.) [Economic Security: Legal, 
Economic, Environmental Aspects. Collection of Scientific Papers of the $4^{\text {th }}$ International Scientific and Practical Conference (Kursk, April 24, 2019)]. Kursk, Yugo-Zapadnyy gosudarstvennyy universitet, 2019, no. EB-04, pp. 309-313.

Alpeeva E.A., Ushenko A.A. Formirovanie kadrov dlya innovatsionno-tsifrovoy ekonomiki [Formation of Personnel for the Innovative Digital Economy]. Globalnyy nauchnyy potentsial [Global Scientific Potential], 2019, no. 4 (97), pp. 154-158.

Balukova V.A., Sadchikov I.A., Somov V.E. Upravlenie innovatsionnymi protsessami na predpriyatiyakh khimicheskoy $i$ neftekhimicheskoy promyshlennosti [Management of Innovative Processes at the Enterprises of Chemical and Petrochemical Industries]. Saint Petersburg, SPbGIEU, 2003. 147p.

Buyanova M.E., Averina I.S. Otsenka vliyaniya faktorov ekonomicheskoy bezopasnosti na innovatsionnuyu aktivnost regiona [Assessment of the Impact of Economic Security Factors on the Innovation Activity of the Region]. Natsionalnye interesy: prioritety $i$ bezopasnost [National Interests: Priorities and Security], 2019, no. 7 (376), pp. 1337-1350.

Gnevko V.A. Regionalnye problemy innovatsionnogo razvitiya ekonomiki [Regional Problems of Innovative Economic Development]. Saint Petersburg, IUE, 2004. 480 p.

Dadalko V.A., Solovkina E.D. Kompetentsii dlya tsifrovoy ekonomiki i transformatsiya obrazovatelnoy sistemy $\mathrm{v}$ usloviyakh VI ekonomicheskogo uklada [Competencies for the Digital Economy and the Transformation of the Educational System in the VI Economic Order]. Natsionalnye interesy: prioritety $i$ bezopasnost [National Interests: Priorities and Security], 2018, no. 5 (362), pp. 913-926.

Dezhina I.G., Saltykov B.G. Mekhanizmy stimulirovaniya kommertsializatsii issledovaniy i razrabotok [Mechanisms for Promoting Commercialization of Research and Development]. Obshchestvo $i$ ekonomika [Society and Economy], 2004, no. 7, pp. 189-248.

Demograficheskiy prognoz po vozrastam na 2019 $2024 \mathrm{gg}$. [Demographic Forecast by Age for 2019-2024]. URL: https://krasstat.gks.ru/folder/ 32970 (accessed 5 March 2020).

Doklad analiticheskogo tsentra pri Pravitelstve Rossiyskoy Federatsii ot 01.06.2019 g. "O tekushchem razvitii proektov $v$ sfere tsifrovoy ekonomiki Rossiyskoy Federatsii» [Report of the Analytical Center from the Government of the Russian Federation Dated June 1, 2019 "On the Current Development of
Projects in the Digital Economy of the Russian Federation"]. URL https://ac.gov.ru/publications ?page $=8$ (accessed 5 March 2020).

Zakon Krasnoyarskogo kraya ot 01.12.2011 g. № 8-3339 «O nauchnoy, nauchno-tekhnicheskoy $i$ innovatsionnoy deyatelnosti v Krasnoyarskom krae» [Law of Krasnoyarsk Krai of December 1, 2011 no. 8-3339 “On Scientific, Scientific-Technical and Innovative Activities in Krasnoyarsk Krai']. URL: http://www.krskstate. ru/docs/0/doc/61927 (accessed 5 March 2020).

Lavrentyeva A.V., DzikiaA.A., KalininaA.E., Frolov D.P., Akhverdiev E.A., Barakova A. S. Iskusstvennyy intellekt i tsifrovye preobrazovaniya $\mathrm{V}$ obshchestve [Artificial Intelligence and Digital Transformations in the Society]. Materialovedenie $i$ inzhenernye nauki [Materials Science and Engineering], 2019, no. 483 , pp. 1-8.

Kapitalizatsiya 100 krupneyshikh kompaniy mira dostigla rekordnykh 21 trillionov dollarov [Capitalization of the Worlds 100 Largest Companies Has Reached a Record 21 Trillion Dollars]. URL: https://www.rbc.ru/business/16/ 08/2019/5d5605839a7947e7cd21723b (accessed 5 March 2020).

Kudryavtseva S.S. Podgotovka kadrov dlya regionalnogo promyshlennogo kompleksa $\mathrm{V}$ usloviyakh tsifrovoy ekonomiki [Training for Regional Industrial Complex in the Digital Economy]. Kazanskiy pedagogicheskiy zhurnal [Kazan Pedagogical Journal], 2019, no. 5 (136), pp. 25-29.

Materialy rasshirennogo zasedaniya prezidiuma Gossoveta $i$ Soveta po nauke i obrazovaniyu ot 06.02.2020 «Rol regionov v podgotovke kadrov dlya ekonomiki i sotsialnoy sfery» [Materials of the Extended Meeting of the Presidium of the State Council and the Council for Science and Education of February 6, 2020 "The Role of Regions in Personnel Training for the Economy and Social Sphere"]. URL: http:// kremlin.ru/events/president/news/62744/work (accessed 5 March 2020).

Melyantsev V.A. Umnye tekhnologii, paradoks Solou i protivorechiya sotsialno-ekonomicheskogo razvitiya $\mathrm{v}$ stranakh zapada i vostoka $\mathrm{v}$ nachale XXI v. [Smart Technologies, the Solow Paradox and the Contradictions of Socio-Economic Development in the West and East at the Beginning of the XXI Century]. Vostok. Afroaziatskie obshchestva: istoriya i sovremennost [Vostok(Oriens)], 2017, no. 3, pp. 162-180.

Nikolaeva I.P. Resursy innovatsiy: organizatsionnyy, finansovyy, administrativnyy [Innovation Resources: Organizational, Financial, 
Administrative]. Moscow, YuNITI-DANA Publ., 2003. 318 p.

Pasport federalnogo proekta ot 28.05.2019 № 9 «Kadry dlya tsifrovoy ekonomiki» [Passport of the Federal Project of May 28, 2019 no. 9 "Personnel for Digital Economy"]. URL: https:// digital.gov.ru/ru/activity/directions/866/ (accessed 5 March 2020).

Perechen obyektov innovatsionnoy infrastruktury [List of Innovation Infrastructure Objects]. URL: http://www.miiris.ru/regions/region_info. php?id=24 (accessed 5 March 2020).

Rezolyutsiya Generalnoy Assamblei OON ot 21.10.2015 «Preobrazovanie nashego mira: Povestka dnya v oblasti ustoychivogo razvitiya na period do 2030 goda» [UN General Assembly Resolution of October 21, 2015 "Transforming Our World: The 2030 Agenda for Sustainable Development"]. URL: http://www.sdgfund.org/ goal-9-industry-innovation-infrastructure (accessed 5 March 2020).

Reyting innovatsionnogo razvitiya subyektov Rossiyskoy Federatsii [Rating of Innovative Development of Subjects of the Russian Federation]. URL: https://issek.hse.ru/rirr2019 (accessed 5 March 2020).

Reyting innovatsionnykh regionov Rossii [Rating of Innovative Development of Subjects of the Russian Federation]. URL: https://i-regions.org/ reiting/rejting-innovatsionnogo-razvitiya/2018 (accessed 5 March 2020).
Slovar innovatsionnykh terminov [Vocabulary of Innovation Terms]. URL: http://infosystems.ru/ library/slovar_ais_1218/slovar_innovaci_ 1222.html (accessed 5 March 2020).

Terebova S.V. Innovatsionnaya infrastruktura $\mathrm{v}$ regione: problemy i napravleniya razvitiya [Innovation Infrastructure in the Region: Problems and Directions of Development]. Ekonomicheskie $i$ sotsialnye peremeny: fakty, tendentsii, prognoz [Economic and Social Changes: Facts, Trends, Forecast], 2014, no. 6 (36), pp. 199-212.

TOP-100 krupneyshikh po kapitalizatsii kompaniy Rossii-Reyting [TOP 100 Largest Companies in Russia by Capitalization - Rating]. URL: https://riarating.ru/infografika/20190129/ 630115992.html (accessed 5 March 2020).

Federalnyy zakon ot 23.08.1996 № 127-FZ «O nauke i gosudarstvennoy nauchno-tekhnicheskoy politike» [Federal Law of August 23, 1996 no. 127-FZ “On Science and State Scientific and Technical Policy"]. Access from Reference Legal System "KonsultantPlyus".

Mitrofanova I.V. et al. Tsifrovizatsiya ekonomiki: mir, Rossiya, regiony [Digitalization of Economy: World, Russia, Regions]. Moscow, Direkt-Media Publ., 2019. 73 p.

Shepelev G.V. Problemy razvitiya innovatsionnoy infrastruktury [Problems of Innovation Infrastructure Development]. Innovatsii, 2005, no. 2 (79), pp. 6-15.

\section{Information About the Authors}

Vladimir I. Byvshev, Candidate of Sciences (Economics), Associate Professor, Department of Economics and Business Processes, Siberian Federal University, Prosp. Svobodnyy, 79, 660041 Krasnoyarsk, Russian Federation; Senior Researcher, Krasnoyarsk Regional Fund for Support of Scientific and Technical Activity, Karla Marksa St., 246, 660100 Krasnoyarsk, Russian Federation, bobbyz@bk.ru, https://orcid.org/0000-0001-5903-1379

Irina A. Panteleeva, Candidate of Sciences (Philosophy), Associate Professor, Department of Advertising and Socio-Cultural Activities, Siberian Federal University, Prosp. Svobodnyy, 79, 660041 Krasnoyarsk, Russian Federation; Executive Director, Krasnoyarsk Regional Fund for Support of Scientific and Technical Activity, Karla Marksa St., 246, 660100 Krasnoyarsk, Russian Federation, panteleevaia@gmail.com,https://orcid.org/0000-0003-3292-0728

Kristina V. Parfenteva, Analyst, Krasnoyarsk Regional Fund for Support of Scientific and Technical Activity, Karla Marksa St, 246, 660100 Krasnoyarsk, Russian Federation, parfenteva@sf-kras.ru, https://orcid.org/0000-0003-2991-2129

Danil I. Uskov, Candidate of Sciences (Engineering), Senior Researcher, Krasnoyarsk Regional Fund for Support of Scientific and Technical Activity, Karla Marksa St., 246, 660100 Krasnoyarsk, Russian Federation, uskov@sf-kras.ru, https://orcid.org/0000-0003-2628-4825 


\section{РЕГИОНАЛЬНАЯ ЭКОНОМИКА}

\section{Информация об авторах}

Владимир Игоревич Бывшев, кандидат экономических наук, доцент кафедры экономики и управления бизнес-процессами, Сибирский федеральный университет, просп. Свободный, 79, 660041 г. Красноярск, Российская Федерация; старший научный сотрудник, Красноярский краевой фонд поддержки научной и научно-технической деятельности, ул. Карла Маркса, 246, 660100 г. Красноярск, Российская Федерация, bobbyz@bk.ru, https://orcid.org/0000-0001-5903-1379

Ирина Анатольевна Пантелеева, кандидат философских наук, доцент кафедры рекламы и социально-культурной деятельности, Сибирский федеральный университет, просп. Свободный, 79, 660041 г. Красноярск, Российская Федерация; исполнительный директор, Красноярский краевой фонд поддержки научной и научно-технической деятельности, ул. Карла Маркса, 246, 660100 г. Красноярск, Российская Федерация, panteleevaia@gmail.com, https://orcid.org/0000-0003-3292-0728

Кристина Владимировна Парфентьева, аналитик, Красноярский краевой фонд поддержки научной и научно-технической деятельности, ул. Карла Маркса, 246, 660100 г. Красноярск, Российская Федерация, parfenteva@sf-kras.ru, https://orcid.org/0000-0003-2991-2129

Данил Игоревич Усков, кандидат технических наук, старший научный сотрудник, Красноярский краевой фонд поддержки научной и научно-технической деятельности, ул. Карла Маркса, 246, 660100 г. Красноярск, Российская Федерация, uskov@sf-kras.ru, https://orcid.org/0000-0003-2628-4825 